- $\quad$ Published: 28 September 2020

\title{
On Soluble Radicals of Finite Groups
}

- S. Yu. Bashun \&

- E. M. Palchik

Ukrainian Mathematical Journal volume 72, pages370-385 (2020) Cite this article

- 22 Accesses

- Metricsdetails

Assume that $\mathrm{G}$ is a finite group, $\pi(\mathrm{G})=\{\mathrm{s}\} \cup \sigma, \mathrm{s}>2, \Sigma$ is a set of Sylow $\sigma$-subgroups in which one subgroup is taken for each pi $2 \sigma$, and $\mathrm{R}(\mathrm{G})$ is the largest normal soluble subgroup in $G$ (soluble radical of $G$ ). Moreover, suppose that each Sylow pi-subgroup $\mathrm{G}_{\mathrm{pi}} \in \sum$ normalizes the s-subgroup $\mathrm{T}^{(\mathrm{i})} \neq 1$ of the group $\mathrm{G}$. In this case, we establish the conditions under which s divides $|R(G)|$.

This is a preview of subscription content, access via your institution.

References

1. 1 .

V. N. Tyutyanov and L. A. Shemetkov, "Triple factorizations in finite groups," Dokl. Nats. Akad. Nauk Bel., 46, No. 4, 52- 55 (2002).

\section{MathSciNet MATH Google Scholar}

2. 2.

É. M. Pal'chik, “On the properties of some prime divisors of the orders of minisotropic tori of finite Lie-type 
groups," Vests. Nats. Akad. Nauk Bel., Ser. Fiz.-Mat. Navuk, No. 4, 66- 71(2012).

3. 3.

É. M. Pal'chik, "Finite simple groups with factorization $\mathrm{G}=\mathrm{G}_{\pi} \mathrm{B}, 2 \notin \pi$, " in: Proc. of the Institute of Mathematics and Mechanics, Ural Branch of the Russian Academy of Sciences, 20, No. 2 (2014), pp. 242- 249 .

4. 4 .

B. Huppert, Endliche Gruppen, I, Springer, Berlin (1982).

\section{MATH Google Scholar}

5. 5.

D. Gorenstein, Finite Simple Groups. An Introduction to Their Classification [Russian translation], Mir, Moscow (1985).

\section{MATH Google Scholar}

6. 6.

D. Gorenstein and R. Lyons, "The local structure of the finite groups of characteristic 2 type," Mem. Amer. Math. Soc., Providence, RI, 42, No. 276, 1- 731 (1983).

7. 7. 
D. Gorenstein, R. Lyons, and R. Solomon, "The

classification of the finite simple groups," Math. Surveys and Monogr., 40, No. 3 (1998).

8. 8.

R. Wilson, The Finite Simple Groups, Springer, London (2009).

\section{Book Google Scholar}

9. 9.

J . H. Conway, R. T. Curtis, S. P. Norton, R. A. Parker, and R. A. Wilson, Atlas of Finite Groups, Clarendon Press, London (1985).

\section{MATH Google Scholar}

10. 10 .

A. S. Kondrat'ev and V. D. Mazurov, "2-Signalizers of finite simple groups," Algebra Logika, 42, No. 5, 594623 (2003).

\section{MathSciNet MATH Google Scholar}

11. 11.

J . G. Bercovich, "On p-group of finite symmetric and alternating group," Contemp. Math., No. 93, 67- 76 (1989).

12. 12 . 
G. Glauberman, Factorizations in Local Subgroups of Finite Groups, Regional Conf. Series in Mathematics, American Mathematical Society, Providence, RI, No. 33 (1977).

13. 13.

B. Huppert and N. Blackburn, Finite Groups, III, Heidelberg, Berlin (1982).

\section{Book Google Scholar}

14. 14 .

E. P. Vdovin and D. O. Revin, "Sylow-type

theorems," Usp. Mat. Nauk, 66, No. 5(401), 3- 46 (2011).

15. 15.

Z. Arad and E. Fisman, “On finite factorizable groups," J . Algebra, 86, No. 2, 522- 548 (1984).

\section{MathSciNet Article Google Scholar}

16. 16.

C. H. Li and X. Li, "On permutation groups of degree a product of two prime powers," Comm. Algebra, 42, 4722- 4743 (2014).

\section{MathSciNet Article Google Scholar}

17. 17. 
J . C. Lennox, E. Stewart, and S. E.

Stonehewer, Subnormal Subgroups of Groups,

Clarendon Press, Oxford (1987).

\section{MATH Google Scholar}

18. 18.

R. Baer, "Kriterien für die Zugehörigkeit von Elementen

zu Ow (G)," Math. Z., No. 152, 207- 222 (1977).

19. 19.

S. Tchounikhin, "Symplicite du groupe finiles orders de ces classes d'elements conjgues," C. r. Acad. Sci., 191, 397- 399 (1930).

\section{Google Scholar}

20.20.

L. S. Kazarin, "On the Chunikhin problem,"

in: Investigation in the Group Theory [in Russian], Ural

Scientific Center, Academy of Sciences of the USSR, Sverdlovsk (1984), pp. 81- 99.

Download references

Author information

Affiliations

1. Polotsk State University, Polotsk, Belarus

$\mathrm{S}$. Yu. Bashun

2. Polotsk State University, Polotsk, Belarus

E. M. Palchik

Corresponding author 
Correspondence to $\underline{\mathrm{S}}$. Yu. Bashun.

Additional information

Translated from Ukrains'kyi Matematychnyi Zhurnal, Vol. 72, No. 3, pp. 326- 339, March, 2020.

Rights and permissions

Reprints and Permissions

About this article

Cite this article

Bashun, S.Y., Palchik, E.M. On Soluble Radicals of Finite Groups. Ukr Math J 72, 370-385 (2020).

https://doi.org/10.1007/s11253-020-01788-9

Download citation

- Received28 March 2019

- Revised09 January 2020

- Published28 September 2020

- Issue DateAugust 2020

- DOlhttps://doi.org/10.1007/s11253-020-01788-9 